\title{
Researching with reciprocity? Meaningful participant-based research in a remote Indigenous community context
}

\author{
Thomas Michel $^{\mathrm{a}}$ and Julie-Ann Bassinder ${ }^{\mathrm{b}}$ \\ ${ }^{a}$ Roper Gulf Shire Council, thomas.n.michel@gmail.com \\ ${ }^{\mathrm{b}}$ Charles Darwin University, jbassinder@hotmail.com
}

\begin{abstract}
In culturally and geographically mainstream settings, evaluation and research of resident satisfaction with local government performance often relies on quantitative research methods, aimed at efficiently obtaining measurable responses and a statistically significant volume of data. Common tools include surveys conducted by phone-, online- and computer-based tools, with random sampling methods applied. This paper argues that these approaches alone are not suitable in a remote Indigenous community setting, and are likely to produce weak results for analytical purposes.

Based on their research experience between 2009 and 2013 in the Northern Territory's Victoria Daly and Roper Gulf Shires concerning local government service delivery and community governance issues, the authors recommend some alternative methodologies and tools for participant-based research in remote Indigenous community settings. Both a scale-based survey and open-ended questions were used, applying techniques such as flexible interviewing in culturally safe environments, deliberate strategies to overcome English language barriers, and remuneration for participants. The aim of the application of these methods was not only to obtain statistically reliable survey results and rich qualitative research data, but also to seek a mutually positive, respectful and beneficial experience between the research participants and researchers. This 'researching with reciprocity' approach may prove to be a useful research tool in other social contexts.
\end{abstract}

\begin{abstract}
Aims
This paper does not aim to report or analyse the results of participant responses during the research project. Instead, focus is on critically discussing the research theories and methodologies underpinning it.

This paper firstly aims to present an overview of mainstream or common performance measurement methods used in Australia's local government sector, and in particular
\end{abstract}


resident satisfaction measurement tools. The Victorian Government's state-wide community satisfaction survey on local government services project is treated as a salient example (JWS Research 2012a).

Secondly, this paper seeks to critique these mainstream methods from theoretical and practical perspectives. This will be undertaken by theoretically positioning mainstream performance measurement methods as an artifact of a positivist approach to social research (particularly in assessments of government programs) and discussing the shortcomings of this approach. This critique is furthered by exploration of the practical limitations of mainstream community satisfaction measurement methods in a remote Indigenous community context.

Thirdly, this paper aims to present the experiences of a three-year community satisfaction research project being undertaken in the Northern Territory's local government sector as a theoretical and practical alternative to mainstream approaches. Mixed research methods, incorporating quantitative and qualitative research tools, and informed by constructivist epistemological philosophies on social research are presented as a more robust, ethical and reciprocal approach for the non-Indigenous researcher to apply when working in a remote Indigenous community setting. This approach allows for principles of participant inclusiveness, knowledge sharing, cultural safety and research reciprocity to enter in to the research process. The authors' research experience is also presented as a practical, effective method of community satisfaction research which has integrated positivist and constructivist approaches to research. The final aim of the paper is to offer the authors' research experience as a useful template for community satisfaction research in other social contexts.

\section{Research setting and methods}

\section{Mainstream methods of community satisfaction research: the Victorian government's community satisfaction survey on local government services}

\footnotetext{
In meditating on the nature of the moral sciences, one cannot help seeing that, as they are based like physical sciences on the observation of fact, they must follow the same method, acquire a language equally exact and precise, attaining the same degree of certainty (Condorcet [1782] in Hacking 1990, p. 38).
}

Research into council performance and resident satisfaction is not a new line of inquiry, and has been an ascendant tool of Australian local government management in recent times. Influential intergovernmental forums such as the Council of Australian Governments (COAG), along with most state governments, have actively encouraged 
performance measurement strategies and initiatives in the local government sector (Worthington \& Dollery 2007). In Victoria, the State Government's Department of Planning and Community Development has supported implementation of a large-scale community satisfaction survey project (JWS Research 2012a), and similar projects have been pursued in other jurisdictions, for example in South Australia through the Local Government Association and State Government (LGA SA 2009).

Worthington and Dollery link the rise of performance measurement in local government with broader microeconomic reforms throughout the Australian government sectors from the 1980s, and argue that application of performance measurement tools in local government (such as resident satisfaction surveys) have become construed as 'fundamental to any economy concerned with the accountability, transparency, efficiency and effectiveness of [public] institutions' (Worthington \& Dollery 2007, p. 4).

The annual community satisfaction survey on local government services project, facilitated by the Victorian Government's Department of Planning and Community Development (DPCD), is examined here as a salient example of a mainstream approach to resident-focused attitudinal research. Data collection tools include computer-assisted, telephone-based surveys that are iterated across large representative random samples. In slightly amended forms, this survey project has been carried out annually since 2001. Its stated aim is to:

seek insight into ways to provide improved or more effective service delivery. The survey also provides Councils with a means to fulfill some of their statutory reporting requirements as well as acting as a feedback mechanism to DPCD (JWS Research 2012a, p. 3).

In 2012, there were 29,384 participants surveyed, with each respondent completing a standard and comparable survey questionnaire. In the report on the survey's findings much emphasis is placed on the quantitatively robust methodology used, which resulted in a maximum margin of error of \pm 0.6 per cent at the 95 per cent confidence level for average results (JWS Research 2012a, p. 7). In empirical terms, this narrow margin of error demonstrates a high level of data reliability and implies the survey information can be meaningfully applied to compare differences in results between councils, geographic areas and sample cohorts.

The Victorian Government's local government survey project exposes both the strengths and weaknesses of positivistic, quantitative-focused social research. On its own terms, the survey provides statistically reliable and valid results, and the researchers are able to determine a relatively narrow sampling error margin. This allows for clear, summarised and authoritative conclusions to be reached from a large volume of data collected. For local government managers and statutory monitoring authorities, these 
survey methods and findings indubitably provide meaningful, comparable information on council performance over time alongside areas for improvement.

Conversely, the quasi-clinical, deductive research methods employed in this social research project - iteration, large-scale random sampling, computer-assisted phone interviews, quantitative interpretation of responses - highlight the extractive and acquisitive approach taken in positivist research. In the Victorian Government's local government survey project, the role or position of the researchers is implicitly linked to the benevolent task of 'providing rational insight into improving service delivery' by 'objectively' measuring attitudinal data using a standardised and tightly scripted questionnaire tool (JWS Research 2012a; JWS Research 2012b). Explicit analysis of the researchers' own bias, subjectivity or position of authority that silently frames each stage of the research process and potentially transforms the perspective on the research matter is ignored - irrespective of the research's stated purpose as a monitoring tool by local government management and the regulatory government authority.

This lack of explicit recognition of bias or the limitations of scripted, telephone-based research by the researchers may be justified as outside the scope of the research project and irrelevant to its intended audience. It may also be critiqued as the recurrent and fundamental trappings of a positivist research approach: the researcher is never the subject of scrutiny or critique, and is assumed to hold superior knowledge, oversight and ethical intent. According to the Maori health academic Linda Tuhiwai Smith, research within this mindset becomes:

...regarded as the domain of experts who have advanced educational qualifications and access to a specialised language and skills... that by definition is developed and supported at a distance from the community (Smith 2012, pp. 127-8).

Political scientist James Scott associates positivist research methods as an extension of modernist ideology, which he defines as a deep-seeded belief in scientific and technical progress, absolute truths and the 'rational' planning of society (Scott 1998, p. 377). The 'rational, objective' researcher and his or her own (re)production of knowledge are a product of this modernist paradigm. Through the 'rational' process of information extraction, summarisation, and standardisation of knowledge, he or she may be promoting the ideal of social order and progress. But this process may also be disallowing alternative sources of knowledge, and discounting the contingent and contestable nature of society (Scott 1998, pp. 88-93; Bevir 2010). The risk in this approach is that it can legitimise social engineering or policy interventions that are informed more deeply by ideology and preconceived, subjective intentions than by a community's own judgement or priorities (Smith 2012, p. 3). 
The positivist researchers' rational approach and implicit discounting of alternative, marginal sources of knowledge may be dismissed as unimportant in the case of a statewide survey of community satisfaction with local government in Victoria. Admittedly, a survey involving tens of thousands of respondents will necessarily lead to a summarisation of information. Arguably, in this example researchers may not be focused on providing discrete narrative space to non-mainstream cultural and linguistic backgrounds, but in finding patterns and convergences.

However, methodological problems emerge if the communities being researched include geographically remote, Indigenous-majority settlements where English is not the first language; contact with mainstream or European culture and government is historically recent and replete with negative encounters; and populations are marginalised from mainstream society in terms of access to resources and services, reflected in poor educational, employment, social and health outcomes. Deep-seeded suspicion of mainstream ideology, cultural practices and intent by government and other outsiders may also be present (Martin 2003; Eckermann et al. 2010; Smith 2012). In this setting, the rational methods employed by positivist social research must be analysed not as a 'common sense' approach, but instead within an epistemologically constructivist approach, as a manifestation of a culturally-laden belief system (Sen 1977a; Sen 1977b; Bryman 2008). The issue of the researcher's position and authority vis-à-vis the research participant becomes paramount (Eckermann et al. 2010; Smith 2012).

Smith explicitly links modernist and positivist (i.e. culturally mainstream) research within an Indigenous cultural context as a form of European imperialism and colonialism, and urges the act of research to be consciously positioned within 'a much larger historical, political and cultural context' (Smith 2012, p. 6). In her words:

It becomes so taken for granted that many researchers simply assume that they as individuals embody this ideal [of benefitting mankind] and are natural representatives of it when they work with other communities. Indigenous peoples across the world have other stories to tell which not only question the assumed nature of those ideals and the practices that they generate, but also serve to tell an alternative story... (Smith 2012, p. 2)

\section{An alternative method of community satisfaction research: beyond a measurement-based approach}

In 2008, the Northern Territory's local government sector underwent far-reaching and unprecedented reform: 53 councils, mainly remote and with small and Indigenousmajority constituencies, were amalgamated into eight regional shires (Michel et al. 2010; Michel \& Taylor 2012). 
Structured academic research into community perceptions of this reform of the local government sector seemed pertinent and pressing: community governance and local decision-making structures regarding council services had been rapidly overhauled, official promises and expectations around improved service delivery were high (McAdam 2007), and there were many anecdotal signs that the reform was unpopular (Smith 2008; Central and Northern Land Councils 2009; Henderson 2009). This led to many research questions: How satisfied were residents with local government services and the new shires? What perceived effects would the reform have on community governance? What areas of local government operations could be improved on? Would levels of community satisfaction change over time?

The authors commenced such research by deciding on a theoretical framework that consciously addressed these subjective, culturally loaded questions. On an epistemological level, a positivist approach to research was rejected in favour of a more constructivist approach, which fundamentally recognises that reality is given meaning through social actors, and is developed and communicated through social contexts (Kayrooz \& Trevitt 2005; Bryman 2008). This approach allows the researcher's own subjectivity to be drawn into question, as well as exploring what role the participants and their messages should play in shaping the research process. Within this framework, the researcher's role is able to become less about measuring truth and acquiring data from people, and more about a collaborative inquiry with people (Altrichter et al. 2002, p. 130). To this end, the authors attempted to be guided by the principles of an 'action research' methodology, and to respect the principles of cultural safety and Indigenist research (Martin 2003; Eckermann et al. 2010).

The key features of action research methodologies are collaboration, power-sharing, respect, reciprocity, and inductive research. Successful research outcomes are linked to action and change, and the process is fundamentally cyclical and continual, allowing for constant reflection, correction and development (Israel et al. 1998, pp. 178-80; Altrichter et al. 2002, p. 130; Denscombe 2008, p. 123; Taylor et al. 2008, pp. 247-8; Grimes 2011, pp. 16-7). Utmost value is placed on the voices and perspectives of participants, and on participants using the knowledge gained in the evaluation process to find their own solutions or pathways to improvement (McNiff et al. 1996; Brydon-Miller et al. 2003; Kindon et al. 2007).

Cultural safety and Indigenist research methodologies are in many ways an extension of this research framework. Their principles seek to promote Indigenous cultural safety and embed research within Indigenous knowledge by: distinctly privileging the Indigenous voice and Indigenous perspectives; recognising the historical, cultural and social contexts in which an intercultural research project is positioned; and seeking to 
minimise power imbalances between the non-Indigenous researcher and the Indigenous research participant (Dodson 1995; Rigney 1997; Dodson 2000; West 2000; Martin 2003; Walter 2005; Arbon 2008; Dudgeon 2008; Eckermann et al. 2010; Ford 2010; Smith 2012). Taking guidance from this methodology was thus an acknowledgement of the ethical issues faced by non-Indigenous researchers working in an Indigenousmajority environment, as flagged by the Australian Institute for Aboriginal and Torres Strait Islander Studies' (AIATSIS) Guidelines for Ethical Research in Australian Indigenous Studies (AIATSIS 2012).

The authors of this paper began in 2009 seeking input and support from local government stakeholders to trial and implement community satisfaction research tools. This period of consultation lasted many months and involved conversations with numerous shire council elected members, local government management staff, and Northern Territory Government officials. As part of this process, efforts were made to critically understand what initiatives and methods for researching community satisfaction in local government was being applied in other jurisdictions. The result of the consultations was the selection of Victoria Daly and Roper Gulf Shire Councils as the two participating local government bodies. In the trial stages (during 2009 and early 2010), as throughout the entire project, the practical content and structure of the research tools were subject to consultation and amendment from research participants in these two Shires.

More fundamental epistemological and ideological questions about the research methodology and aim of the project were also addressed. Many of these concerned the sensitive and challenging intercultural issues of non-Indigenous researchers working in Indigenous communities. Some Indigenous scholars report of Indigenous people having a low regard of research and their practitioners, and feelings of exploitation by the research process born by experience: Indigenous people have generally been given the subordinate role of research subjects in the process, their communities have often been heavily researched over time, and they are able to claim that little tangible benefits have accrued for them from their involvement (Rigney 1997; Martin 2003; Smith 2012).

The practical considerations for the authors were: If the research aims and methods had first been drafted by outside non-Indigenous researchers, what input would the mainly Indigenous participants and their communities have in development of the research tools? What value, if any, would the research provide to their communities? How would their message be recorded and reported? How would participating communities be able to control or instrumentalise the research findings?

However, another important participant group and target audience for the research findings was senior management in the two Shires. This group has been responsible for 
providing in-kind support including travel expenses, and logistical and operational assistance to the research work. Pragmatically, this group is potentially a key facilitator in implementing any changes that may be advocated by community participants during the research process. How could this research project maintain independence over strategic priorities and simultaneously address senior management's information requests?

Faced with these potentially competing interests and the researchers' own research agendas and cultural assumptions, what research methods should the researchers apply, and how should the research tools be designed? Could power imbalances between the non-Indigenous researchers and Indigenous participants be not only acknowledged, but challenged? How could the research project give respect and value to all participants?

The researchers' decision to consciously address these issues and adopt a constructivist methodological approach, guided by the principles of action research and cultural safety and Indigenist research - an approach already used by some academics and practitioners in Indigenous health, law and education research (see for example Dudgeon 2008; Eckermann 2010; Grimes 2011) - had a number of practical implications for how the authors conducted their research. Firstly, it became clear that many of the research methods and approaches applied in, for example, the Victorian Government's local government community satisfaction survey would be unhelpful in the remote Indigenous communities of the Victoria Daly and Roper Gulf Shires. Due to unreliable household telephone services, English language barriers, and other inhibiting cultural factors, a tightly scripted, telephone-based survey format was discarded as an inappropriate research tool. At the same time, it was not possible to have the evaluation transform into something that was entirely community driven, as the decision to assess the impact of the local government reforms had already been made.

In its place, the researchers decided to conduct all participant-based research inperson with adult participants in their resident communities. The researchers generally spent between two and four days in each community. Participants were interviewed either as individuals or in small groups at the discretion of participants, with emphasis being placed on making the setting as safe and comfortable as possible for participants to feel supported and strong. In most cases, only one researcher was present for each interview, and participation was confidential from Shire managers and, if necessary, from others, requiring researchers to have an awareness and sensitivity to community politics. Accessible and culturally safe locations were chosen for interviews, such as in front of the community store or in an open public area. All participants, however, were given the opportunity to choose the location of the interview to ensure their control over privacy, cultural safety, support, legitimacy and authority. The researcher only 
approached participants' private dwellings if invited, and respected community protocols such as approaching, where possible, the 'right' person for permission to proceed with interviews in the community. Further, if a funeral or other cultural ceremony was occurring in a community, or if any other social-political community sentiment emerged that demanded space and privacy the researchers as a rule postponed their visit.

Language interpreters were also allowed for and used to a limited extent. Interestingly, however, most participants (and interpreters) seemed reluctant to use this facility for this particular research project. This observed reluctance may have stemmed from a number of factors, including: the contentious nature of the subject matter (and participants' desire to keep their responses confidential); local political sensitivities; gender, generational and authority differences between participant and interpreter; clan and family divisions; relationships of avoidance; and participants' pride in their English language skills. It may also be that the available language interpreters introduced new relationship complications of which the researchers were not made aware. This can be considered one of the challenges of working in cross-cultural environments: applying an ethic of inclusiveness does not erase the networks of affiliation and enmity that may be present in the social setting being researched.

However, the researchers consciously did not want to discriminate on who participated in the research based on English language fluency. In order to compensate for the lack of language interpreter use, concerted attempts and revisions were made to format and language content of the research tools, with the aim of making them easily comprehensible to most participants. Furthermore, as participants were given control to manage the interview process, many chose group interviews surrounding themselves with supportive family and kinship relations. This had some positive effects on the research: Firstly, if one participant's English language skills were weaker than others in the group, a group interview format allowed peers to effectively interpret and translate that participant's responses. ${ }^{1}$ Secondly, it allowed for some participants to participate who might otherwise have not felt comfortable or confident enough being interviewed one-on-one by a non-Indigenous researcher. Thirdly, a group interview format served to subtly alter the power dynamic in the interview: the Indigenous participants were in the majority, and would often shape and direct communication on their own terms. The researchers often experienced groups conducting extended conversations in Indigenous languages before formulating a final response in English.

\footnotetext{
${ }^{1}$ In certain individual interviews, participants called on other community members outside the interview to translate or validate their responses to the researcher. This can also be interpreted as a positive sign of participants seeking control over the interview process.
} 
Two distinct research tools were applied as components of a mixed-method approach (Bryman 2008, pp. 610-23) (see Appendix 1). The first was a list of approximately 10 open-ended questions that were aimed at exploring participants' perceptions about the Shires, how decision-making in their community had changed due to local government reform, and their perspective on the Shires as a new political institution. ${ }^{2}$ Flexibility was adopted with this tool, and Shire Council elected members and staff were invited annually to provide feedback and amendments to the questions, and participants were given the same opportunity during and after the interview process. Emphasis in some of the questions was on being open-ended, allowing participants to raise issues or opinions as they saw fit. For example, one of the opening questions was: 'When you hear the word “shire”, what do you think of?' This allowed participants to start with as broad or as narrow a response as desired, and re-create the question according to the participants' own reality and set of priorities. It also set the dynamic of the researcher as listener and the participant as knowledge holder. Some participants even embraced the control of the interview from the outset, and did not wait for questions. Instead, the interview was commenced by instructions on what the participant perceived to be the important issues and information the researcher should know on the topic.

The second research tool was a survey on service delivery, with questions grouped into seven service areas and response options structured by an ordinal scale. In order to promote research validity, comparability and the benefits of iteration, the format and content of this tool has remained standardised and relatively unchanged over the lifetime of the research project. This has enabled opportunities for more statistical-based research enquiries to be undertaken, such as t-test experiments on whether levels of satisfaction with local government services have improved significantly over time since the reform. However, in order to remove any potential abstraction or confusion with the use of a numeric scale, textual tags were used for each of the scale's digits, and the numbers were not mentioned. A score of very bad was interpreted as $=1$, bad $=2$, OK $=3$, good $=4$, and very good $=5 .^{3}$

\footnotetext{
${ }^{2}$ Prior to local government reform in 2008, none of the local government councils in Indigenous-majority, rural-remote regions of the Northern Territory were Shires, and only a few local government bodies had any regional structures or geographic reach. The overwhelming majority of pre-2008 councils in these regions were single-settlement, non-contiguous community councils with populations under 1,000 residents. Therefore, the term 'Shire' was very much a new concept in governance and administrative structure in these local government areas, and represented a distinct break with past models.

${ }^{3}$ Adjustments were made at the time of interview to allow for different socio-linguistic interpretations of the term 'bad', due to a perceived reluctance amongst some participants to use the term. One participant explained that to say something is 'bad' means it is to be feared like a bad and unchangeable spirit. This meaning obviously had different connotations than what the researchers intended in the services survey scale. This problem of divergent meanings was mitigated through the substitution of the terms 'very bad' and 'bad' with 'really not good' or 'not good', which some participants seemed to be much more comfortable using to judge service standards.
} 
The use of a scale-based survey tool was partly a pragmatic decision, based on local government management's appetite for quantifiable data on council performance. However, it opened another more structured pathway for participants to inform the researcher about what services were performing well in their community, and what services needed improving. This tool was also a way to focus discussion on what Shires presently do, elicit information on participants' more immediate and tangible experiences with Shires' operations, and to distinguish between attitudes towards local government services versus the more problematic and contentious issues surrounding community governance. Further, it highlighted where contrasts exist between the Shire and community perceptions, experiences and expectations of Shire services. However, the authors contend that sole use of this survey tool without being coupled with a more exploratory and inductive research tool would have been too deductive to be either a meaningful or a culturally safe and ethical tool in this research setting.

Each interview and survey took between approximately 30 to 60 minutes to conduct, based on the level of detail the participant wanted to communicate. To compensate for the time and information imparted by the participants, the researchers made the decision to remunerate participants $\$ 20$ per interview. This was a somewhat contentious action, and provoked extra deliberation during the university human research ethics committee's evaluation of the research project based on the committee's concerns that financial compensation of participants may undermine the integrity and reliability of the interview process. However, for ethical and practical considerations, the researchers maintain that participant remuneration has been a sound component of the project's research tools.

On ethical grounds, a small act of financial compensation for participants was intended as an acknowledgement that a professional transaction was taking place. A small financial payment also conveyed the message that the time, information and knowledge imparted by the participant were important, respected and valuable. Over the life of this project, the researchers received some financial recompense and support for their labours. While the researchers could not offer stable income streams for participants, it was considered fair participants should receive a proportionately similar remuneration.

Practically, financial remuneration of participants facilitated a much more effective fieldwork research process than was likely without any remuneration. Little effort or time on behalf of the researchers was needed to recruit participants, and interviews could generally be intensively conducted over the entire course of a working day. This meant that during a two- or three-day visit to a community, a reasonable sample could be collected with minimal difficulty. Arguably, it also lessened the risk of non-sampling error by mitigating non-response bias. In other words, providing financial remuneration 
provided a motivation to participate which arguably improved the randomness of sampling and minimised the potential effect of the 'squeaky wheel sampling syndrome', whereby a strongly opinionated minority with time on their hands would be more motivated to participate in the project, skewing results. Conversely, it should be acknowledged that providing financial remuneration for participants may have also created a sampling bias skewed towards a selection of residents motivated by monetary reward. However, despite being conscious of this risk during the research, the researchers did not note any evidence of sampling bias based thereon.

An important final step in the project's research methodology was to report back the results of the research to the affected communities, Shire staff and elected Shire Councils. This occurred through presentations to Council meetings, follow-up meetings with management staff, and, where possible, meetings with local boards or committees in participating communities. The data was presented mainly verbally and through visual presentations, with supporting documentation made available. Further, where appropriate, a short verbal summary of what their peers across the two Shires were saying was given to participants at the conclusion of the interview. This aspect of the project was an important feature in the principles of action research and culturally safe Indigenist research as a cyclical learning process: by providing research participants with a final summary of the information and knowledge gained from the project, it allowed these groups to reflect on and instrumentalise the findings for their own strategic or learning purposes.

\section{Findings}

The authors' overall experience with the tools and methods used in this research project has been positive and productive. In almost all the communities visited, there were no problems with obtaining sufficient consenting participants for the research, and most participants seemed willing and satisfied to generously share their time and opinions. There were few negative comments from participants or community residents received about the research, and most commonly this related to suspicions that nothing would be done with the research and feedback to participants would be lacking. These criticisms may have been partly allayed by the researchers explaining when and where results would be reported back, and that the researchers would visit again in a year's time to follow up with more interviews. 
When the research results were reported back to Shire elected officials, management staff or community-based local boards, the audiences were generally very receptive. ${ }^{4}$ In certain instances, where findings suggested criticisms, the data was closely scrutinised and the researchers interrogated at length about their findings. Both of the Shire Councils have also (to varying degrees) incorporated the results of the research into their strategic and operational planning. However, some participants' responses to the feedback were critical and pessimistic: many agreed with the veracity of the reported results and findings, but remained frustrated by the lack of a clear plan of action to instrumentalise their information for change, or that the criticisms expressed about the new Shire structure were not being adequately addressed or communicated to the right kinds of audience.

The researchers have also been successful in obtaining reasonably large and detailed participant samples from the two Shire populations. Since 2009, 659 adult residents have participated in the research project, and a further round of interviews in Roper Gulf Shire communities is scheduled for 2013 with a target participant sample of 160. This translates into close to five per cent of the adult population in the Victoria Daly and Roper Gulf Shires participating annually in this research project (see Table 1). The authors contend that this is a reliable and statistically significant sample of these populations.

Further, these samples were able to be obtained within a relatively short timeframe. As previously stated, the researchers generally only spent two to four days conducting interviews in each community. There was little experience with a lack of availability of consenting participants, and the researchers' work schedule during their community visits was generally intensive and busy.

Conversely, the methods used in this project may be criticised for not adhering strictly to the principles of action research and Indigenist research. David Selener describes the role of research within an Action Research framework as:

a process through which members of an oppressed group or community identify a problem, collect and analyse information, and act upon the problem in order to find solutions and to promote social and political transformation (quoted in Reason \& Bradbury 2006, p. 1).

By this definition, the authors' project fell short of this role. The researchers were, and remain non-Indigenous outsiders. Although participants were able to engage in the research by controlling the content and priorities expressed during interviews, they were not directly involved in setting the research agenda or timeframe, or interpreting and

${ }^{4}$ However, because much of the content was critical and even negative towards the Shires, it was observed that the information did at times cause some vexation and indignation amongst Shire elected leaders and management staff especially. 
distributing the findings. Fieldwork visits to participating communities remained relatively fleeting which, considered in isolation, arguably did not support the development of longer-term relationships between researchers and participants. ${ }^{5}$ The feedback process was done pragmatically and on occasion within a limited timeframe, and the researchers did not involve themselves in fomenting politically transformational action based on the research findings. ${ }^{6}$ It is therefore debatable whether the project participants truly became transformative agents of change through their involvement with the research, or whether they merely played the role of respected informants.

Tab. 1. Research Project Adult Participation Rates, 2009-13, Victoria Daly and Roper Gulf Shires.

\begin{tabular}{lcc}
\hline Year 1: 2009-10 & Victoria Daly Shire & Roper Gulf Shire \\
\hline Dates & Jan - Apr 2010 & Dec 2009 \\
\hline Communities & 10 & 1 \\
\hline Participant No. & 151 & 26 \\
\hline
\end{tabular}

\begin{tabular}{lcc}
\hline Year 2: 2010-11 & Victoria Daly Shire & Roper Gulf Shire \\
\hline Dates & Feb 2011 & Dec 2010 - Jul 2011 \\
\hline Communities & $16^{*}$ & 10 \\
\hline Participant No. & 138 & 174 \\
\hline
\end{tabular}

\begin{tabular}{lcc}
\hline Year 3: $\mathbf{2 0 1 2}$ & Victoria Daly Shire & Roper Gulf Shire \\
\hline Dates & May 2012 & May - Jul 2013 \\
\hline Communities & $16^{*}$ & 10 \\
\hline Participant No. & 170 & 172 \\
\hline
\end{tabular}

\begin{tabular}{lcc}
\hline 2011 Census Data & Victoria Daly Shire & Roper Gulf Shire \\
\hline $\begin{array}{l}\text { Estimated total adult population } \\
(18 \text { years or older)** }\end{array}$ & 3,612 & 3,898 \\
\hline $\begin{array}{l}\text { Estimated total Indigenous } \\
\text { population** }\end{array}$ & $79.2 \%$ & $81.8 \%$ \\
\hline
\end{tabular}

* This includes outstations and homelands.

** Based on 2011 ABS Census data (ABS 2013a; ABS 2013b).

\footnotetext{
${ }^{5}$ However, the repeated visits over three years by one of the researchers in particular, and the sharing of sometimes intimate and sensitive stories have led to some trust-based and long-term relationships developing beyond the scope of the research project.

${ }^{6}$ For a discussion of the tensions between political action, advocacy and the researcher that is common in action research-inspired projects, see Holcombe (2008).
} 


\section{Conclusions and recommendations for policy and practice}

In our experience, the suite of mixed methods and tools employed in the Victoria Daly / Roper Gulf Shires’ community satisfaction research project have proven to be a meaningful strategy for non-Indigenous researchers conducting research with an Indigenous-majority group of participants living in remote and marginalised communities of the Northern Territory. It has also demonstrated a valid, practical and effective alternative to a purely positivist research approach. Reciprocity and respect was sought between the researchers and participants. The information gathered was rich, detailed, and appeared to be genuinely reflective of participants' own perspectives and priorities. The focus on qualitative-based research tools allowed participants to flexibly and comfortably convey their attitudes, and attempted to avoid a dominant nonIndigenous cultural bias in the research. A reliable and statistically significant sample was obtained. And the findings of the research were shared and followed up with participants.

Overall the project has been a positive experience for the researchers and (based on participant feedback) for the participants as well. As a direct result of this project, one of the authors has also become more closely involved with one Aboriginal community development corporation in the Roper Gulf Shire region and is developing a more deeply reciprocal and respectful co-researcher relationship with its members on the topic of governance tensions.

The core recommendation of this paper is that academic and non-academic researchers working in marginalised Indigenous communities should reject a purely positivist research approach as unsuitable, ineffective and even unethical. This is not to say that techniques for 'evidence-based policy', including those of trustworthy review, should be jettisoned. Instead, the (especially non-Indigenous) researcher should be obliged to critically reflect upon their own privileged position in the research process, and what cultural assumptions, political agendas, policy priorities and ideologies they may be inherently supporting. This is especially pertinent in Australia's Indigenous sector, where non-reciprocal, interventionist engagement (however progressive and benevolent its intentions may be) is an established approach to policy development and engagement (Altman \& Hinkson 2007; Hunt et al. 2008; Lea 2008; Sullivan 2008; Lea \& Pholeros 2010). Linda Tuhiwai Smith challenges all non-Indigenous researchers working with Indigenous people to 'clarify their research aims and think more seriously about effective and ethical ways of carrying out research with indigenous peoples... [and develop] ways of working with indigenous peoples... in an ongoing and mutually beneficial way' (Smith 2012, p. 17). 
More broadly, this paper's critique of a positivist research approach recommends that mixed method research, consistent with a constructivist epistemology and a combination of qualitative and quantitative research tools, is generally a more robust and suitable research approach in many other social settings (and not just in remote Indigenous communities). For example, research into community satisfaction and residents' attitudes towards local government may benefit significantly from applying methods and tools beyond high-volume, telephone-based, tightly scripted survey interviews lasting five to ten minutes. The philosopher Baudrillard warns that 'like dreams, statistics are a form of wish fulfilment' (Baudrillard [1987] 1990, p. 147). This should serve as a caveat to researchers who believe measuring equates to understanding, and whose aim is to create statistics from people's ethereal attitudes, opinions and perceptions.

\section{References}

Altman, J.C. \& Hinkson, M. (eds) 2007, Coercive Reconciliation: Stabilise, Normalise, Exit Aboriginal Australia, Arena Publications, Melbourne.

Altrichter, H., Kemmis, S., McTaggart, R. \& Zuber-Skerritt, O. 2002, 'The concept of action research', The Learning Organization, vol. 9, no. 3, pp. 125-31.

Arbon, V. 2008, 'Indigenous Research: Aboriginal Knowledge Creation', Ngoonjook, no. 32, pp. 80-94.

Australian Bureau of Statistics (ABS) 2013a, 2011 Census Quick Stats: Roper Gulf (S), ABS, viewed 5 May 2013, <http://www.censusdata.abs.gov.au/census_services/ getproduct/census/2011/quickstat/LGA73600?opendocument\&navpos=220>.

ABS 2013b, 2011 Census Quick Stats: Victoria Daly (S), ABS, viewed 5 May 2013, <http://www.censusdata.abs.gov.au/census_services/getproduct/census/2011/quicksta t/LGA74500?opendocument\&navpos=95>.

Australian Institute for Aboriginal and Torres Strait Islander Studies (AIATSIS) 2012, Guidelines for Ethical Research in Australian Indigenous Studies, 2nd edn, AIATSIS, Canberra, viewed 7 October 2013, <http://www.aiatsis.gov.au/research/docs/GERAI S.pdf $>$.

Baudrillard, J. ([1987] 1990), Cool Memories, 1980-1985, Verso, New York.

Bevir, M. 2010, Democratic Governance, Princeton University Press, Princeton, NJ.

Brydon-Miller, M., Greenwood, D. \& Maguire, P 2003, 'Why Action Research?’, Action Research, vol. 1, no. 1, pp. 9-28.

Bryman, A. 2008, Social Research Methods, Oxford University Press, Oxford.

Central and Northern Land Councils 2009, 'CLC: rebuild community governance urgently’, Land Rights News, Darwin, September. 
Denscombe, M. 2008, The Good Research Guide: for small-scale social research projects, 3rd edn, Open University Press, Berkshire.

Dodson, M. 1995, 'Indigenous peoples and intellectual property rights', in Ecopolitics IX: Conference Papers and Resolutions, Northern Land Council, Darwin, pp. 30-6.

Dodson, M. 2000, 'Human Genetics: Control of Research and Sharing of Benefits', Australian Aboriginal Studies, no. 1/2, pp. 56-64.

Dudgeon, P. 2008, 'Empowering Research with Indigenous Communities', Ngoonjook, no. 32, pp. 8-26.

Dowd, T., Chong, E., Nixon, L. \& Gray, G. 2010, Binan Goonj: Bridging Cultures in Aboriginal Health, 3rd edn, Elvesier Australia, Chatswood, NSW.

Ford, P.L. 2010, Aboriginal Knowledge Narratives and Country: marri kumkimba putj putj marrideyan, Post Pressed, Queensland.

Grimes, B. 2011, Strong foundations for community based legal education in remote Aboriginal communities, National Association of Community Legal Centres, Sydney, viewed 29 August 2012, <http://www.naclc.org.au/cb_pages/files/Strong\%20 Foundations\%20-\%20NAAJA's\%20

Legal\%20Development\%20Methodology1\%20-\%20AGLC\%20referencing.pdf>.

Hacking, I. 1990, The Taming of Chance, Cambridge University Press, Cambridge.

Henderson, A. 2009, 'Legal action launched against super shire', ABC News, 11 December, viewed 16 October 2013, <http://www.abc.net.au/news/stories/2009/ 12/11/2769098.htm>.

Holcombe, S. 2008, 'Constraints on researchers acting as change agents', in J. Hunt, D.E. Smith, S. Garling \& W. Sanders (eds), Contested Governance: Culture, Power and Institutions in Indigenous Australia, Monograph No. 29, Centre for Aboriginal Economic Policy Research, ANU E Press, Canberra, pp. 55-71.

Hunt, J., Smith, D., Garling, S. \& Sanders, W. (eds) 2008, Contested Governance: Culture, power and institutions in Indigenous Australia, Monograph No. 29, Centre for Aboriginal Economic Policy Research, ANU E Press, Canberra.

Israel, B.A., Schulz, A.J., Parker, E.A. \& Becker, A.B. 1998, 'Review of CommunityBased Research: Assessing Partnership Approaches to Improved Public Health', Annual Review of Public Health, vol. 19, pp. 173-202.

JWS Research 2012a, Statewide Local Government Services Report, Department of Planning and Community Development [Vic], viewed 13 March 2013, $<$ http://www.dpcd.vic.gov.au/localgovernment/publications-and-research/data,directories-and-surveys>. 
JWS Research 2012b, CSS Questionnaire 2012, Department of Planning and Community

Development [Vic], viewed 13 March 2013, <http://www.dpcd.vic.gov.au/_data/ assets/pdf_file/0016/114208/2012-DPCD_CSS_Questionnaire.pdf>.

Kayrooz, C. \& Trevitt, C. 2005, Research in Organisations and Communities: Tales from the real world, Allen \& Unwin, Crows Nest, NSW.

Kindon, S., Pain, R. \& Kesby, M. 2007, Participatory Action Research Approaches and Methods: Connecting people, participation and place, Routledge, London.

Lea, T. 2008, Bureaucrats and Bleeding Hearts: Indigenous Health in Northern Australia, UNSW Press, Sydney.

Lea, T. \& Pholeros, P. 2010, 'This Is Not a Pipe: The Treacheries of Indigenous Housing', Public Culture, vol. 22, no. 1, pp. 187-209.

Local Government Association of South Australia (LGA SA) 2009, Comparative Performance Measurement Project, LGA SA, viewed 16 October 2013, $<$ http://perform.lga.sa.gov.au/loadlga/pages/MainPage>

Martin, K.L. 2003, 'Ways of Knowing, Ways of Being and Ways of Doing: a theoretical framework and methods for Indigenous re-search and Indigenist research', Journal of Australian Studies, vol. 76, pp. 203-14.

McAdam, E. 2007, New local government structure announced, media release, Northern Territory Government, Darwin, 30 January.

McNiff, J., Lomax, P. \& Whitehead, J. 1996, You and Your Action Research Project, Routledge, London and New York.

Michel, T. \& Taylor, A. 2012, 'Death by a thousand grants? The challenge of grant funding reliance for local government councils in the Northern Territory of Australia', Local Government Studies, vol. 38, no. 4, pp. 485-500.

Michel, T., Gerritsen, R. \& Thynne, I. 2010, Northern Territory Scoping Study, Australian Centre of Excellence for Local Government, University of Technology, Sydney.

Reason, P. \& Bradbury, H. 2006, 'Introduction: Inquiry and participation in search of a world worthy of human aspiration', in P. Reason \& H. Bradbury (eds), Handbook of Action Research, concise paperback edn, Sage Publications, Thousand Oaks, CA, pp. $1-14$

Rigney, L.I. 1997, Internationalisation of an Indigenous Anti-colonial Cultural Critique of Research Methodologies: A Guide to Indigenist Research Methodology and Its Principles, Flinders University of South Australia, Adelaide.

Scott, J.C. 1998, Seeing like a State: how certain schemes to improve the human condition have failed, Yale University Press, New Haven and London. 
Sen, A. 1977a, 'Rational Fools: A Critique of the Behavioural Foundations of Economic Theory', Philosophy and Public Affairs, vol. 6, no. 4, pp. 317-44.

Sen, A.K. 1977b, 'On Weights and Measures: Informational Constraints in Social Welfare Analysis', Econometrica, vol. 45, no. 7, pp. 1539-72.

Smith, D. 2008, 'Cultures of governance and the governance of culture: transforming and containing Indigenous institutions in West Arnhem Land', in J. Hunt, D. Smith, S. Garling \& W. Sanders. Contested Governance: Culture, power and institutions in Indigenous Australia, Monograph No. 29, Centre for Aboriginal Economic Policy Research, ANU E Press, Canberra, pp. 75-111.

Smith, L.T. 2012, Decolonizing Methodologies: Research and Indigenous people, 2nd edn, Zed Books, London.

Sullivan, P. 2008, 'Bureaucratic process as morris dance: an ethnographic approach to the culture of bureaucracy in Australian aboriginal affairs administration', Critical Perspectives on International Business, vol. 4, no. 2/3, pp. 127-41.

Taylor, J., Wilkinson, D. \& Cheers, B. 2008, Working with communities in health and human services, Oxford University Press, Melbourne.

Walter, M. 2005, 'Using the "power of the data” within Indigenous research practice', Australian Aboriginal Studies, vol. 2, pp. 27-34.

West, E.G. 2000, 'An alternative to existing Australian research and teaching models The Japanangka teaching and research paradigm - an Australian Aboriginal mode', $\mathrm{PhD}$ thesis, Southern Cross University, Lismore, NSW.

Worthington, A. \& Dollery, B. 2007, The Application of Performance Measurement in Australian Local Government, Working Paper Series 17-2007, University of New England, Armidale, NSW. 


\section{Appendix 1. Interview and survey documents}

\section{Introductory questions}

1. Which community do you normally live in?

2. Do you know who the councillor(s) is(are) in your shire or ward? What about the mayor?

3. Do you normally vote? Did you vote for someone locally to be a councillor or mayor in the last election? Would you run for council?

\section{Key questions}

4. When you hear the word 'shire', what do you think of? What does local government mean to you?

5. What do you think is the role of the shire?

6. Are core local government services (rubbish, local roads, parks and gardens etc.) improving?

7. Do you think that there have been more jobs and training opportunities created in the last 12 months? Do you have a job? Would you like to see more jobs and training? What sort of jobs and training?

8. Do you think that the shire staff are listening to the issues in your community and getting things done?

9. Do you feel like you and your community find out enough about the decisions made by council?

10. Do you feel that you and your community are given enough opportunity to participate in the decisions made by council?

11. Do you have a local board? What do you think it does? Do you know a member of the board or know who the chair is?

12. What would you like to see the shire do for the community?

\section{End question}

13. What is your vision for the future of your community? How would you like to see it in the future? 


\section{Appendix 2. Local government survey framework, 2013}

\section{Topic: services}

\section{Community:}

Completion date:

\section{Standard interval scale}

$\begin{array}{lll}\text { Very bad } & \oplus:) & 1 \\ \text { Bad } & :(-) & 2 \\ \text { OK } & \oplus & 3 \\ \text { Good } & \oplus & 4 \\ \text { Very good } & \oplus ; & 5\end{array}$

\section{Group:}

Evaluator:

\begin{tabular}{|c|c|c|c|c|}
\hline Category & Sub-group & Evaluation question & Average score & Comments \\
\hline \multirow{6}{*}{$\begin{array}{l}\text { Local roads and related } \\
\text { infrastructure }\end{array}$} & Roads & How good are the local roads inside your community? & & \\
\hline & & Could you explain why you feel this way? & & \\
\hline & Drainage & $\begin{array}{l}\text { How good is the drainage in your community? (When it rains, does the water stay } \\
\text { around a long time?) }\end{array}$ & & \\
\hline & Street lighting & How good is the street lighting in your community at night? Is there enough? & & \\
\hline & $\begin{array}{l}\text { Street signage and traffic } \\
\text { safety }\end{array}$ & How good are the traffic safety and road signs in your community? & & \\
\hline & Pedestrian safety & How good is pedestrian safety? Why? & & \\
\hline \multirow[t]{3}{*}{ Waste management } & Rubbish removal & How good is the rubbish collection from the bin outside your house? & & \\
\hline & Litter pick-up & $\begin{array}{l}\text { How good are the council and community at picking up litter around your } \\
\text { community? }\end{array}$ & & \\
\hline & Landfill & How well is the rubbish dump taken care of? & & \\
\hline
\end{tabular}




\begin{tabular}{|c|c|c|c|}
\hline Category & Sub-group & Evaluation question & Average score \\
\hline \multirow[t]{4}{*}{ Housing repairs and maintenance } & Housing standard & How good is the house you live in? & \\
\hline & $\begin{array}{l}\text { Housing repairs and } \\
\text { maintenance }\end{array}$ & $\begin{array}{l}\text { If something in your house is getting old or something is broken, how good is the } \\
\text { council at fixing it or putting in a new one? }\end{array}$ & \\
\hline & \multirow[t]{2}{*}{ Housing program } & $\begin{array}{l}\text { Do you think the Strategic Indigenous Housing and Infrastructure Program/Housing } \\
\text { mob have done a good job? }\end{array}$ & \\
\hline & & Did you get a new house or a refurbishment? & \\
\hline \multirow[t]{3}{*}{ Parks, reserves and open spaces } & Parks and reserves & How good are the parks and reserves in your community? & \\
\hline & Playgrounds & How good are the playgrounds in your community? & \\
\hline & Sports oval & How good is the sports oval? & \\
\hline $\begin{array}{l}\text { Community Development } \\
\text { Employment Projects (CDEP) }\end{array}$ & $\begin{array}{l}\text { CDEP (delivered in only } 6 \\
\text { communities) }\end{array}$ & How good is CDEP? How could it improve? & \\
\hline \multirow[t]{2}{*}{ Animal welfare and control } & Domestic animals & How good is the dog (or cat) control in your community? & \\
\hline & Feral animals and livestock & How good is the feral animal and livestock control in your community? & \\
\hline \multirow[t]{8}{*}{ Other community services } & Sport and recreation & $\begin{array}{l}\text { How good are the sport and recreation activities in your community? What could } \\
\text { make them better? }\end{array}$ & \\
\hline & Night patrol & How good is the night patrol in your community? What could make it better? & \\
\hline & Youth services & How good is the youth engagement program? What would make it better? & \\
\hline & Aged care & How good is the aged care service in your community? What could make it better? & \\
\hline & Child care & How good is the child care service in your community? What could make it better? & \\
\hline & Library services & How good is the library service in your community? What could make it better? & \\
\hline & $\begin{array}{l}\text { Rapid Intensive Brokerage } \\
\text { Support (RIBS) }\end{array}$ & How good is the RIBS program? What would make it better? & \\
\hline & Cultural activities & $\begin{array}{l}\text { If the council helps out with cultural activities, how good does it help out? What could } \\
\text { make it better? }\end{array}$ & \\
\hline Governance & Local boards & Do you know about the local board? How good is the local board? Are they working? & \\
\hline Overall & Overall & Altogether, how good do you think the shire services are in your community? & \\
\hline Other government departments & Overall & How well do you think the other government departments are doing? & \\
\hline
\end{tabular}

